\section{SIR JOHN LUBBOCK ON ANTS}

GIR JOHN LUBBOCK read two papers on ants at the Limnean Society on February 6 . The first gave an account of their anatomy ; but from the extreme complexity of these in. teresting little creatures, it would be impossible to make this communication intelligible without the figures. The second paper was a continuation of his observations on the habits of ants. He mentioned that he had at first isolated his nests by means of water. This was effectual enough, but, especially in summer, the water required to be continually renewed. Kerner, however, had suggested that the hairs of plants served to prevent ants from obtaining access to the honey, and it accordingly occurred to him that strips of fur arranged with the points of the hairs downwards might answer his purpose. He had tried this, and finding it successful, he thought a similar arrangement might perhaps be found useful in hot countries.

It is generally stated that the queen ants alone lay eggs, but Sir John has found that in most of his nests some few of the workers are capable of doing so. It appears, however, that these eggs always produce males. In the case of bees we know that the queen is fed on a special kind of food. In ants it is not feasible to make observations similar to those by which in bees this has been established. It is, however, rendered more than probable by the fact that while males and workers have been bred by hundreds in his nests, no queen has yet been produced.

It is well known that ants keep other species of insects in their nests, which they use just as we do cows, \&c.

The Mat. p. l'Hist. prim. de l'Homme for $x 869$ contains a short but interesting account by $M$. Lespes of some experiments made by him on the relations existing between ants and their domestic animals, from which it might be inferred that even within the limits of a single species some communities are more advanced than others. He found that specimens of the blind beetle, Claviger duvalii, which always occurs with ants, when transferred from a nest of Lasizus niger to another which liept none of these domestic beetles, were invariably attacked and eaten. From this he infers that the intelligence necessary to keep Clavigers is not coextensive with the species, but belongs only to certain communities and races, which, so to say, are more advanced in civilisation than the rest of the species.

Sir John Lubbock, however, removed specimens of the curious blind Platyarthmis from one nest to another, but they were always amicably received. He even transferred specimens from a uest of Lasius flaves to one of Fornica fusca, with the same result.

As regards the longevity of ants he has now two queens of $F$. fuscr, which seen quite in good health and which have lived witli him since 1874 ; they are therefore probably five years old. He has also workers of Lasius niger, Fomnica sangininea, $F$. fusca, and $F$. cincrea, which he has had under observation since 1875 .

In his previous papers he had given various instances which som to show that ants do not exhibit such unvarying lindness to theil friends as has been usually supposed. He wished to guar himself, however, against being supposed to question the general good qualities of his favourites. In fact, ants of the same nest never quarel among themselves; he had never seen any evidence of ill-temper in any of his nests. All is harmony. He inad already in previous papers given various instances of render kindness. Again, in one of his nests of Formica fusca, was poor ant which had come into the world without antenne. was a poor ant which had come into the world without antenna. with leisth one day he found her wandering about in an aimless sort of nizuner, and apparently not knowing her way at all. After a wile she fell in with some specimens of Lasius flavus, who directly attacked her. He then set himself to separate them ; but she was evidently much wounded, and lay helplessly on the ground. A fier some time another Formica fusca from her nest came by. She examined the poor sufferer carefully, then picked her up teinderly, and carried her away into the nest. It would have been difficult, Sir John thinks, for any one who witnessed this scene to have denied to this ant the possession of humane feelings.

It is clear from the experiments recorded in the present and in Sir John's former papers, that the ants recognise all their fellows in the same nest, but it is very difficult to understand how this can be effected. The nests vary very much in size, but in some species 100,000 individuals may probably be by no means an unusual number, and in some instances even this is largely exceeded. Now it seems almost incredible that in such cases every ant knows every other one by sight; neither does it seem possible that all the ants in each nest should be characterised from those of other nests by any peculiarity. It has been sug. gested in the case of bees that each nest might have some sign or password. The whole subject is full of difficulty. It occurred to Sir John, however, that experiments with pupa might throw some light on the subject. Although the ants of every separate nest, say of Formica fusca, are deadly enemies, still if larva or pupa from one nest are transferred to another, they are lindly received and tended with, apparently, as much care as if they really belonged to the nest. In ant warfare, though sex is no protection, the young are spared-at least when they belong to the same species.

Moreover, though the habits and dispositions of ants are greatly changed if they are taken away from their nest and kept in solitary confinement, or only with a few friends, still under such circumstances they will often carefully tend any young which may be confided to them. Now if the recognition were effected by means of some signal, or password, then, as it can hardly be supposed that the larvæ or pupæ would be sufficiently intelligent to appreciate, still less to remember it, the pupæ which were intrusted to ants from another nest would have the password, if any, of that nest, and not of the one from which they had been taken. Hence, if the recognition were effected by some password, or sign with the antenna, they would be amicably received in the nest from which their nurses had been taken, but not in their own.

He therefore took a number of pupr out of some of his nests of Formica fusca and Lasius niger, and put them in small glasses, some with ants from their own nest, some with ants of another nest of the same species. The results were that thirtytwo snts belonging to Formica fusca and Lasius niger, removed from their nest as pupa, attended by friends and restored to their own nest, were all amicably received. What is still more remarkable, of twenty-two ants belonging to Fornicica fusca, removed as pupa, attended by strangers and returned to their own nest, twenty were anicably received. As regards one Sir John was doubtful; the last was crippled in coming out of the pupre case, and to this, perhaps, her unfriendly reception may have been due. Of the same number of Lasius niger developed in the same manner from pupa tended by strangers belonging to the same species, and then returned into their own nest, seventeen were amicably received, three were attacked, and of about two Sir John felt doubtful.

On tize other hand, fifteen specimens belonging to the same species, removed as pupre, tended by strangers belonging to the sane species and then put into the strangers' nest, were all attaclieti.

The results may be tabulated as follows :-

$\begin{gathered}\text { Pupa brought up by friends and } \\ \text { Peplaced in their own nest. }\end{gathered}$
Put back in own uph but in strangers.

Attaclied

Received nest. nest.

Sir John intends to make further experiments in this direction, but the above results seaw very interesting. They appear to indicate that ants of the same nest do not recognise one anothei by any password. On the other hand, if ants are removed from the nest in the pupre state, tended by strangers, and then restored, some at least of their relatives are certainly puzzled, and in many cases doubt their claim to consanguinity. Strangers, under the same circumstances, would be immediately attacked; these ants, on the contrary, were in every case-sonetimes, however, aftei examination-amicably received by the majority of the coloniy, and it was often several hours before they came across one who did not recognise them.

\section{UNIVERSITY AND EDUCATIONAL INTELLIGENCE}

THE Medical Faculty of the University of Zurich gave, last week, the degree of M.D. to Miss Draya Sjocie, from Shabats, in Servia, and the Countess Vilma Hugonai, from Teteny, Hungary.

THE success of the high classes for ladies at Odessa has exceeded all expectations. On the opening day, January 21 , instead of the expected sixty or seventy students, 215 ladies were inscribed. The University has offered its rooms for the classes. I Of about three of these Sir John did not feel sure. 
WE learn from the Annual Report of the Moscow University that the number of students at the University was, during 1878 , 1,643 , with 108 professors; 318 of them were in the Jurispru. dence Faculty, $13 \mathrm{I}$ in the Philological, 240 in the Physico-Mathematical, and 954 studied Medicine. No less than 62 medical students have taken part in the last war; the majority of students are very poor, and 417 of them received pecuniary help which has reached, during the year, the sum of II, $500 \%$.

\section{SCIENTIFIC SERIALS}

American Fournal of Science and Arts, January, 1879.-Prof. Loomis's important paper in this number on storms on the Atlantic, \&c., has been noticed elsewhere. Prof. Marsh (in an appendix) describes a new order of extinct reptiles (Sauranodonta) from the Jurassic formation of the Rocky Mountains; they closely resemble Ichthyosaurus (of which no remains have hitherto been found in America), but are without teeth. The same author continues his "Principal Characters of American Jurassic Dinosaurs."-Prof. Greene, of Troy, New York, describes a paper dome constructed from his plans for an astronomical observatory. The paper covering is in sixteen equal sections, the framework of each section consisting of three ribs of pine meeting at the apex. There are also a circular sill at the base and two parallel semicircular arch girders spanning the dome (all of pine). The entire structure weighs about 4,000 1bs. The dome is supported on six 8-inch balls rolling between grooved iron tracks by direct pressure.-Mr. Edison describes his tasimeter as applied to measuring the heat of the stars and of the sun's corona.-Mr. Fontaine writes on the mesozoic strata of Virginia, and Mr. Holden on the brightness and stellar magnitude of the third Saturnian satellite.-A list of fifty species of east coast fishes (many of them new to the fauna) is supplied by Messrs. Goode and Blan. - In the "Miscellaneous Intelligence" will be found the report of the committee appointed to consider the scientific surveys of the United States territories.

\section{SOCIETIES AND ACADEMIES LONDON}

Royal Society, January 23.- "On the Microrheometer." By J. B. Hannay, F.R.S.E., F.C.S., lately Assistant Lecturer on Chemistry in the Owens College, Manchester. Communicated by H. E. Roscoe, LI.D., F.R.S., Professor of Chemistry in Owens College, Manchester.

In this paper the author reviews the work done by chemists and physicists in determining the relation between the chemical composition of a liquid and its rate of flow through a capillary tube. Poiseiulle ${ }^{x}$ ascertained, in a very accurate manner, all the physical laws relating to the rate of flow, as regulated by temperature, pressure, and dimensions of the tube; but on examining saline solutions he could make nothing of the numbers presented, because he used percentage solutions instead of solutions proportional to the equivalent of the body dissolved. Graham, ${ }^{2}$ noticing that Poiseiulle had discovered a hydrate of alcohol by running various mixtures of alcohol and water through the tube, examined mixtures of the various acids with water, and found that the hydration proceeded by distinct steps of multiple proportions. Several others, notably Guerout, ${ }^{3}$ have since worked on the same subject, but as they have only worked on organic liquids, and have done all the rates at the same temperature, the results throw no light on the phenomena. Thus water runs about five times as quickly at $100^{\circ}$ as at $0^{\circ}$; and in a series of alcohols, such as Guerout experimented upon, the differences between their boiling points were very great, so that, their vapour tensions or molecular mobilities being quite incomparable while at the same temperature, the experiments do not admit of any real interpretation. The author reserves the organic part of the investigation, which requires the determination of vapour tensions, till a future paper, and in the present deals with saline solutions.

The phenomenon of the flow of liquids through capillary tubes has been called in this country transpiration, while in other countries no distinct name has been adopted; and as the English word is already in use in French for another purpose, and pro. perly applies to gases (the laws relating to which are quite different), the author proposes to use for liquids the term

\footnotetext{
I Ann. de Chim. et de Physique, [3], t. vii. 50

Phil Trans., 186x, p. 373 .
}

3 Comptes Rendus, Ixxix. p. x20x; lxxxi, p. 1025.
"Microrheosis," from $\mu \iota \kappa \rho t$ 's and $\rho \hat{e} \omega$, the instrument being called the microrheometer. The form of apparatus which the author finally adopted is figured in the paper, and is so arranged that when the liquid is introduced, as many experiments as may be desired may be tried, and the pressure and temperature, as well as the atmosphere in which the experiment is conducted, may be varied, while the thermometer indicating the temperature is at the mean point of the system. The author gives a curve for water from $0^{\circ}$ to $100^{\circ}$, the differences of rate being smaller as the temperature rises.

Various salts are then examined, being dissolved to form "normal" solutions; but as the solubility of some salts is too low for such solutions, the effect of the amount of salts dissolved is determined. This is found to be directly proportional to the amount of salt in solution. Values for many salts in solution are then given, each number being the mean of ten experiments, and the probable jerror of the mean is calculated in each case. The conclusions arrived at are these. The rate of flow does not depend on any of the "mechanical" features of the salt, such as crystalline form, specific volume, solubility, \&c.; but upcn the mass of the elements forming the substance and the amount of energy expended in its formation. Each element has a value of its own, which is continued in all its compounds. Thus all the salts of potassium and sodium formed by the same acids have a constant difference. In like manner each metalloid and acid radicie has a value which is continued in all its combinations. Then the greater the combining value of an element the quicker is its microrheosis; thus potassium has a higher rate than sodium, barium than strontium, strontium than calcium, and so on. The microrheosis also varies with the amount of energy in the compound; thus nitrates stand highest, as they contain most energy ; then chlorides; and, lastly, sulphates, which are exhausted compounds.

The instrument, bringing to light as it does the fundamental relations of combining weight and energy in chemical action, will be of the utmost importance in chemical physics, as by its use not only will the amount of energy evolved in reactions be determined, but the mass combined; or, in other words, the chemical equivalent of the elements involved will be found.

February 6. - "On certain Dimensional Properties of Matter in the Gaseous State." By Osborne Reynolds, F.R.S., Professor of Engineering at Owens College.

Mathematical Society, February I3.-C. W. Merrifield, F.R.S., president, in the chair.-Sir J. Cockle, F.R.S., wa admitted into the Society.-Mr. R. Hargreaves and Prof. W. E. Story were proposed for election.-DDr. Hirst, F.R.S., communicated a paper by $M$. Halphen on the number of conics which satisfy five independent conditions.-Sir J. Cockle spole upon a construction for making magic squares. Messrs. Cayley, Harley, Henrici, Roberts, Hart, and other gentlemen to $-\mathrm{l}$ yari in a discussion on the subject. Prof. Henrici, F.R.S., ave some properties of frames.-Prof. H. I. S. Smith, F.K.S., read two papers on a modular equation and on the formula for four Abelian functions. - Mr. J. J. Walker communicated a quaternion proof of Minding's theorem.

Linnean Society, February 6.-Prof. Alman, F.R.S., president, in the chair.-Mr. J. R. Jackson exhibited specimens from the tombs of ancient Thebes. Among these were fruits of the Doum Palm (Hyphane thebaica) and of H. aigun, formerly, but wrongly, described as an Areca. Small berries also obtained were identified as those of Funiperns phanticea as against those of F. excelsa.-Mr. J. G. Baker showed dried bulbs of Buphane toxicarea, which furnish a principal ingredient of the poison the Bushmen of South Africa tip their arrows with. Structurally, the numerous tunics of the bulb are a peculiarity. The range of this plant has been found to be as far north as Lake Tanganyika. In Sir C. W. Strickland's hothouse a plant flowered: last year, and this for the first time in England.-Mr. W. T. Thiselton Dyer shortly described specimens of, and pointed out the special characters and probable advantages of, a new fodder grass, Euchlona luxurians, and he also exhibited and made remarks on curious instruments used for weaving fibre of Curcue. ligo latifolia by the natives of Borneo.-Mr. T. Christy drew attention to a sample of tea grown in Natal, and to a bottle of the milky secretion of the African Rubber Tree (Landolphia), the same having been freshly drawn from the living plant and immediately thereafter forwarded to this country ; slight coagulation of the juice had nevertheless occurred.-The Rev. G. Henslow passed round for examination a specimen of female 